\title{
En torno a las dimensiones del espacio público: el caso de la Ciudad Autónoma de Buenos Aires*
}

\author{
Around the dimensions of public space: \\ the case of the Autonomous City of Buenos Aires
}

Claudia Berta Santaló**

Universidad de Buenos Aires

Recibido: 18 de enero de 2020

Aceptado: 16 de marzo de 2020

\section{RESUMEN}

En este artículo se indaga en torno a las dimensiones del espacio público reflexionando acerca de las distintas perspectivas desde donde concebir las actuaciones sobre el mismo. Se toma el caso de la Ciudad Autónoma de Buenos Aires donde en los últimos años se han realizado obras necesarias en el espacio público que contribuyen al mejor funcionamiento de la ciudad y al crecimiento de ciertos estándares en la calidad de vida. Sin embargo hoy pareciera ser otra la perspectiva necesaria para entender las prioridades de la ciudadanía.

Palabras clave: espacio público, dimensiones, perspectivas, situación social, estallido social, Buenos Aires.

\begin{abstract}
The idea of this article is to inquire about the different dimensions of the public space and explore which of the potential perspectives we have to take in consideration when you have to work in it. The city of Buenos Aires is taken as a model. In the last years, the local government has been building several public spaces improving its performance and quality standards. However, nowadays, another perspective is needed to observe the public space and appreciate the real problems of the citizens.
\end{abstract}

Key words: public space, dimensions, perspectives, social situation, social outbreak, Buenos Aires.

\footnotetext{
* Antecedentes del documento. Este artículo forma parte de una investigación personal, efectuada sobre la Ciudad Autónoma de Buenos Aires (CABA) como coordinadora de obras desarrolladas desde el Gobierno de la Ciudad, en el espacio público de dicha ciudad.

** Claudia Berta Santaló. Arquitecta (Universidad de Buenos Aires). Magíster en Políticas Territoriales y Ambientales, Universidad de Buenos Aires, Argentina.
} 


\section{Introducción}

Reflexionar sobre el espacio público implica adentrarse en alguna o varias de las dimensiones que lo componen, acentuando la mirada en lo físico, lo social, lo cultural y/o lo político descubriendo distintas perspectivas y lógicas urbanas desde donde concebir las actuaciones sobre el mismo.

Desde un aspecto jurídico, se podría definir al espacio público en oposición al espacio privado, con una regulación específica impartida por parte de la administración pública que fija las condiciones de utilización y de instalación de actividades. (Segovia y Jordán, 2005) Desde la lógica funcional, en cambio, se piensa al espacio público como organizador y articulador de la estructura urbana. Se lo asimila al lugar de tránsito entre diversos puntos de la ciudad, así como también aparece frecuentemente como sinónimo de espacio verde donde prima la visión paisajística tradicional que asocia el espacio público específicamente a los parques o plazas.

Puede considerarse también al espacio público como el escenario donde se desarrollan las actividades de los ciudadanos: un lugar para la manifestación y el encuentro social donde se satisfacen necesidades urbanas colectivas que trascienden los límites de los intereses individuales de los habitantes de la ciudad. (Segovia y Jordán, 2005)

Para el arquitecto Oriol Bohigas, "el espacio público es la ciudad y la ciudad es un fenómeno esencialmente político" (Bohigas, 2008). Para Jordi Borja, el espacio público supone dominio público, uso social colectivo y multifuncionalidad. Por lo tanto, asevera que debe ser concebido como instrumento de redistribución social, cohesión comunitaria, facilitador de las relaciones sociales y estimulador de la integración cultural. El autor define al espacio público como el espacio de la representación y el conflicto. (Borja, 2003)

En la misma línea, Carrión habla del espacio público como contenedor de la conflictividad social, como un componente fundamental para la organización de la vida colectiva y destaca el derecho al espacio público como el derecho a la inclusión y el respeto al otro en el uso de un mismo espacio. De esta manera añade un nuevo aspecto al considerar al espacio público como lugar de aprendizaje de la alteridad. (Carrión, 2004)

Como señala García Canclini, durante el siglo XX se vieron ejemplos del espacio público concebido como defensa de lo social frente al poder capitalista, donde lo público fue la garantía de los derechos civiles, sociales y económicos conquistados. Así, García Canclini presenta al espacio público como espacio de resistencia al Estado autoritario y a los poderes no representativos y discrecionales del capital, en la defensa de los intereses comunes de los miembros de una sociedad (1997).

El concepto de espacio público se podría también relacionar a la triada conceptual sobre el espacio social elaborada por Henri Lefebvre. En la misma el autor define la "práctica espacial" de una sociedad como el espacio percibido, remitiendo a lo que ocurre en las plazas y calles o sea en el espacio público y su uso por parte de los habitantes. Interpreta a la "representación del espacio" como aquel concebido por los urbanistas, arquitectos, diseñadores al servicio de una ideología donde el espacio se organiza desde el poder. Finalmente enuncia al "espacio de representación" como el espacio vivido a través de las imágenes y símbolos que lo acompañan, conformando así el espacio de los sometimientos a las representaciones dominantes pero también en el que se originan las resistencias y deserciones. (Lefebvre, 2013)

Con la observación de algunos casos en forma más específica, es probable que se puedan identificar dos o más dimensiones del espacio público superpuestas, así como también es posible descubrir cual prevalece en un momento específico. En este trabajo la propuesta es ahondar en el caso de la ciudad de Buenos Aires y su espacio público observando algunas de las obras, tanto estructurales como puntuales realizadas en el último tiempo. Obras necesarias que contribuyen al mejor funcionamiento de la ciudad y al crecimiento de ciertos estándares de la calidad de vida, como el aumento de metros cuadrados de espacios verdes por habitante. ${ }^{1}$ Pero a su vez se propone reflexionar 
sobre el espacio público desde otra perspectiva que ilumine sobre las pistas que van apareciendo y transforman a ese espacio en contenedor y reflejo de un malestar social y de desigualdades que requieren prontas respuestas por parte de los gobernantes.

\section{La ciudad autónoma de Buenos Aires y su espacio púbico}

La megaciudad de Buenos Aires está conformada por la Ciudad Autónoma de Buenos Aires (C.A.B.A.) como "municipio nuclear" (Vapñarsky, 1996) y su conurbación organizada en distintas unidades administrativas según tres cordones o anillos de crecimiento. La ciudad nuclear con una superficie de 203 km2, presenta la mayor concentración de población y el mejor nivel relativo en cuanto a provisión de servicios, infraestructura y equipamiento. ${ }^{2}$

Desde 1947 la población de la ciudad de Buenos Aires se ha mantenido casi constante rondando los 3 millones de habitantes. Sin embargo resulta interesante destacar que el Censo Nacional de Población y Vivienda considera a la población "nocturna". Si el Censo midiese la población presente y diurna de un día de semana se evidenciaría un gran aumento desde 1947 cuando el conurbano tenía 1741338 habitantes, al 2010, año del último censo, con 9916715 habitantes, $\left(1^{\circ}\right.$ y $2^{\circ}$ anillos compuestos por 24 municipios $)^{3}$. Gran parte de esa población es la que realmente utiliza la infraestructura de la ciudad nuclear que funciona como el centro de toda el área metropolitana. Según datos del Gobierno de la Ciudad más de 3500000 personas ingresan diariamente a la ciudad desde el conurbano bonaerense. (Dirección General de Estadísticas y Censos, 2019)

En los últimos 4 años, la ciudad ha experimentado importantes cambios en su espacio público. Se han puesto en valor plazas paradigmáticas del centro de la ciudad y se han creado nuevos espacios verdes en los barrios. También se realizaron importantes obras de infraestructura vial alrededor de las cuales se han desarrollado nuevos espacios públicos. Estas obras mejoraron la accesibilidad, disminuyeron la contaminación ambiental y sonora y, sobre todo, han creado espacios públicos de calidad.

\section{Programa "Buenos Aires sin barreras"}

La CABA fue fundada respondiendo a las pautas urbanísticas establecidas en las Leyes de Indias, introducidas en América en el momento de la conquista. A través de esas pautas se estructuró la ciudad en damero con la manzana como unidad de repetición. A mediados del siglo XIX los ingleses realizaron el tendido ferroviario dando origen a poblados básicamente rurales ubicados en las zonas altas que se fueron transformando en cabeceras de distritos en torno a las estaciones de tren. Así el área metropolitana se desarrolló en base a un esquema radiocéntrico con núcleo en la ciudad de Buenos Aires y el puerto y ejes a lo largo de las vías ferroviarias. La manzana como unidad básica de la trama se repitió indefinidamente.

En los últimos años, una de las obras más importante respecto al espacio público y, como parte del programa de actuación "Buenos Aires sin barreras", comprendió la elevación en viaducto de las vías de las distintas ramas ferroviarias que atravesaban toda la ciudad. La construcción de estos viaductos radicaron en obras de una compleja ingeniería para eliminar el uso de barreras en cruces vehiculares y abriendo nuevas calles para la circulación vehicular y peatonal. Además, los viaductos incluyeron la elevación de las estaciones de pasajeros. Hasta el momento se realizaron obras en las líneas del ferrocarril Mitre, línea Tigre y el ferrocarril San Martín. Con las obras en la línea San Martin ( $5 \mathrm{kms}$ de vías elevadas), se eliminaron 11 barreras y se abrieron $11 \mathrm{ca}-$ lles. Con la elevación de las vías del Ferrocarril Mitre (3,9 kilómetros) se excluyeron 8 barreras ferroviarias y se abrió el paso de 4 calles que antes se interrumpían por las vías. Debajo del viaducto se generaron nuevos espacios públicos verdes, zonas de servicios y se instaló mobiliario urbano y zonas de juegos para niños, habiéndose habilitado hasta el momento dos nuevas estaciones elevadas.

En total, además de generar nuevos espacios de recreación se incorporaron aproximadamente 5,2 hectáreas al tejido urbano en el bajo viaducto de la línea Mitre y 10 hectáreas en el de la línea San Martín. Se 
obtuvieron también beneficios suplementarios como el incremento de los servicios de trenes debido a la posibilidad de aumentar su rapidez sin afectar la circulación vehicular y dar fin a las interferencias ferroviarias con la actual traza de la red vial. (Figuras 1 y 2 )

\section{Parque lineal del Bajo y otras obras puntuales}

El área central de la Ciudad Autónoma de Buenos Aires comprende al núcleo histórico y financiero de la ciudad, concentrando además las funciones administrativas del gobierno, tanto nacional como municipal. Ha sido a través de la historia y sigue siendo el escenario paradigmático de las reivindicaciones sociales y expresiones políticas populares. En los últimos 20 años, además, se ha generado en el área una concentración de los equipamientos, funciones y actividades de comando y de vinculación entre la economía nacional y la global. (Ciccolella, Mignaqui, 2009)

Otra obra importante sobre el espacio público realizada en el último tiempo fue el desarrollo del Parque lineal del Bajo ${ }^{4}$ que sumó 3,8 hectáreas de espacios verdes al área central y la unió peatonalmente con Puerto Madero. Hasta hace unos años, terminales de colectivos y avenidas con tránsito prioritario de camiones, por la cercanía del puerto, impedían una correcta conexión entre esta área de la ciudad y el mencionado barrio de Puerto Madero. ${ }^{5}$

Con el Parque del Bajo se creó un eje verde peatonal desde la avenida Belgrano hasta la avenida Corrientes, de aproximadamente 800 metros. En este tramo se convirtió el área de estacionamiento del edificio de la Aduana en un parque con amplias veredas $y$ nuevo equipamiento y alumbrado, se recuperaron para el uso público los jardines del edificio del Ministerio de Defensa mediante el corrimiento de las rejas que lo bordeaban; se creó un gran parque dando marco al monumental edificio que alberga al Centro Cultural Kirchner (ex Correo Central) revalorizando elementos patrimoniales existentes y relocalizando al monumento homenaje a Juana Azurduy. Debajo de este parque se construyó un estacionamiento subterrá- neo para albergar la playa de regulación de transporte público de pasajeros que antes funcionaba en su superficie.

A partir de este proyecto, una explanada con una amplia escalinata conecta la Casa de Gobierno con el barrio de Puerto Madero cruzando la autopista que ahora corre en trinchera y desembocando en el Puente de la Mujer. ${ }^{6}$ Se logra de esta manera, unir el centro histórico de la ciudad con el barrio más nuevo de la misma.

Una bicisenda (o ciclovía) convive a lo largo de todo el eje verde con senderos peatonales y calles de convivencia. El desarrollo paisajístico se funda en la incorporación de plantas nativas, nuevo equipamiento de calidad, renovación del alumbrado con tecnología led y la valorización de elementos de valor patrimonial ya existentes. (Figuras 3 , 4 y 5)

Otras obras de carácter más puntual se han desarrollado en los barrios transformando espacios vacantes en nuevas plazoletas. Plaza Clemente se construyó en un predio baldío transformándolo en un lugar de paseo y esparcimiento acorde a los consensos arribados con los vecinos del barrio. Tres ejes dominaron su diseño: el recrear a nivel paisaje las tres ecorregiones naturales del área donde se asienta la ciudad (selva marginal, bosque xerófilo y pastizal pampeano), el diseñar espacios accesibles para todos (se instalaron planos hápticos, rampas y senderos especiales para discapacitados, así como juegos inclusivos) y el reflejar a través de una línea de tiempo la historia e identidad barrial. A partir que su nombre rememora al personaje Clemente de la tira cómica creada por el artista Caloi, el proyecto se pensó como una mancha rosa, cuya forma evoca a los dibujos de los comics, esparcida entre el verde de la vegetación nativa. (Figura 6)

La nueva plaza conocida como Manzana 66 se creó en el barrio con menos espacios verdes de la ciudad, como un nuevo lugar de recreo y actividades al aire libre incluyendo en una esquina una escuela para el barrio (actualmente en construcción). El espacio público se dividió conformando un gran patio de juegos y un espacio de contemplación recreando con parterres de plantas nativas 
Figura 1. Estación Belgrano “C” de la línea Mitre del ferrocarril, nuevo viaducto. Ciudad Autónoma de Buenos Aires, 2019.

Fuente: https://www.buenosaires.gob.ar/desarrollourbano/desarrollo/viaducto-mitre

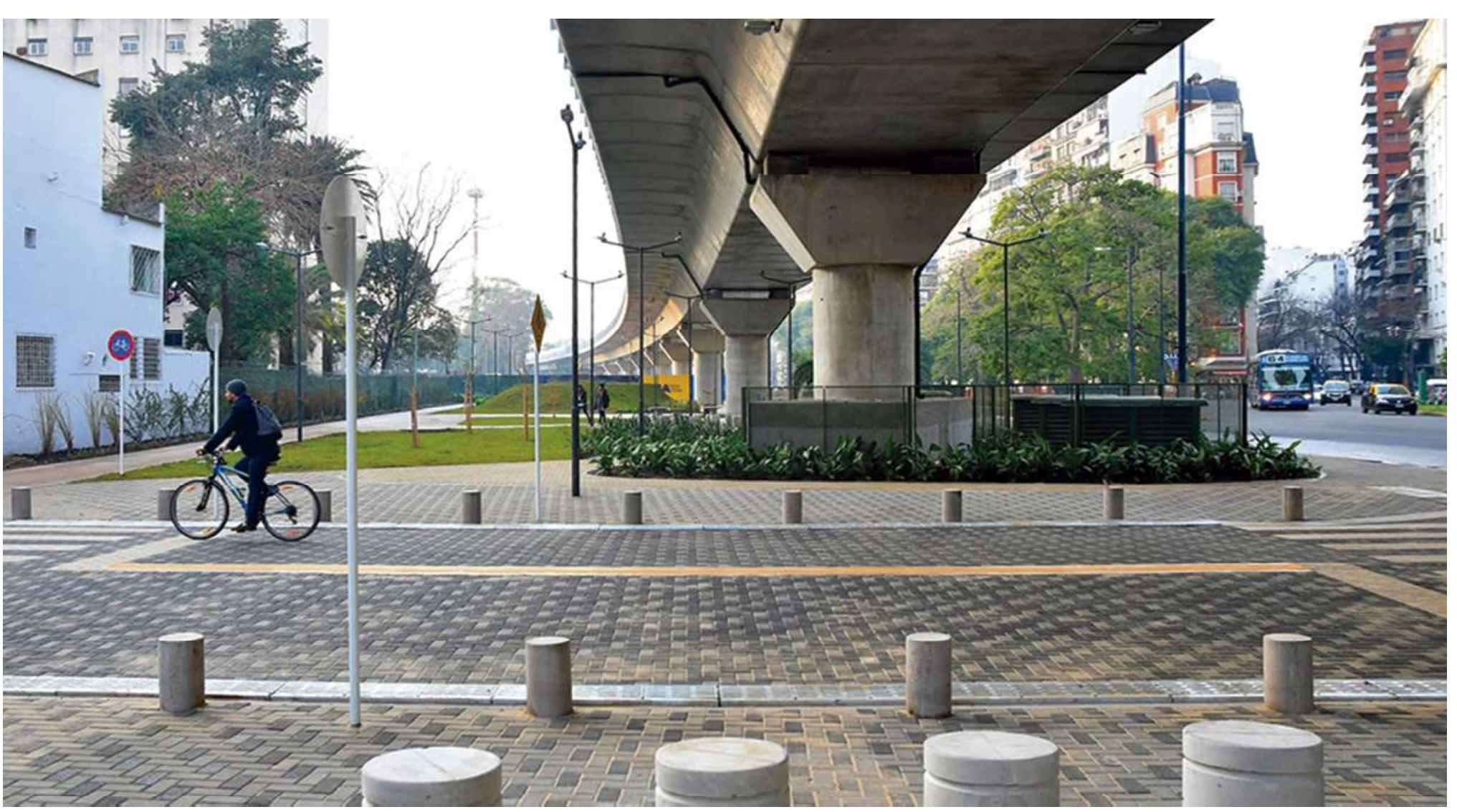

Figura 2. Nuevo espacio público en el bajo viaducto de la línea Mitre del ferrocarril, por donde corrían las vías.

Ciudad Autónoma de Buenos Aires, 2019. 


\section{ARQUITEXTOS}

ISSN 1819-2939 / ISSNe 2706-8099

Año 27, No 35, enero-diciembre de 2020, 25-36

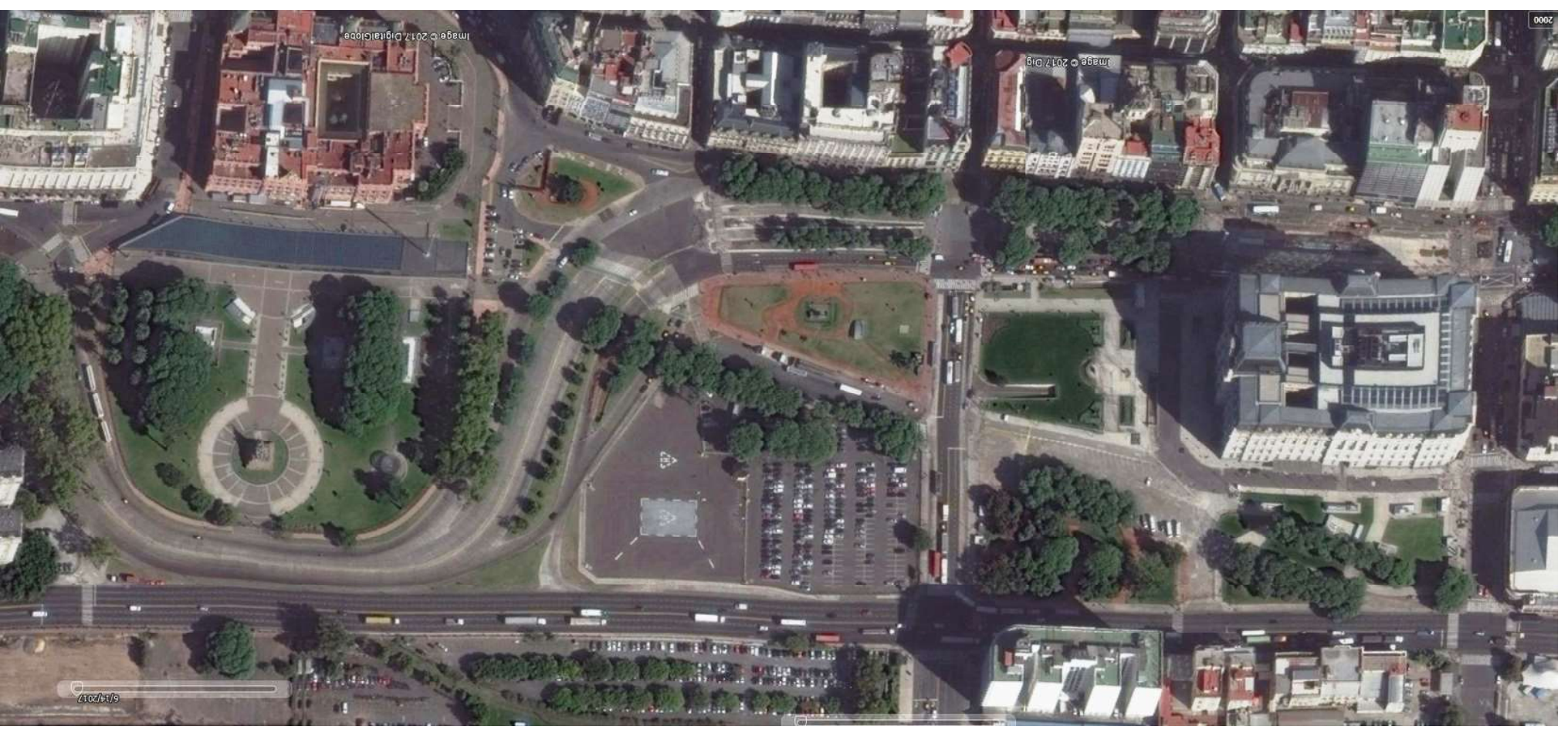

Figura 3. Fotografía aérea con sector Casa de Gobierno, área de estacionamiento frente al edificio del Centro Cultural Kirchner, ex Correo Central. Ciudad Autónoma de Buenos Aires, 2017.

Fuente: Dirección General de Proyectos de Arquitectura, Ministerio de Desarrollo Urbano, GCBA.

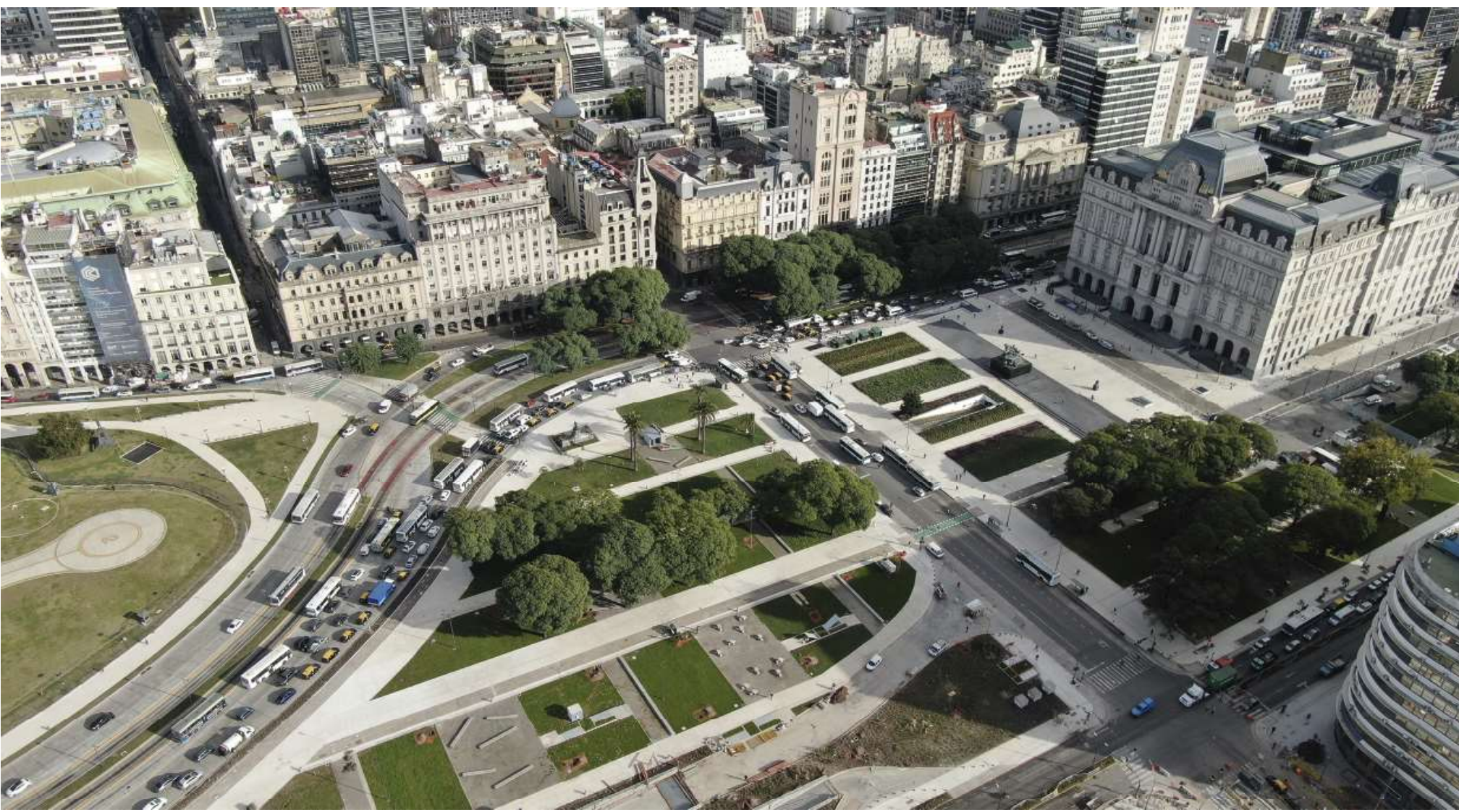

Figura 4. Fotografía aérea con sector Parque lineal del Bajo y áreas verdes frente al edificio del Centro Cultural Kirchner.

Ciudad Autónoma de Buenos Aires, 2019.

Fuente: Dirección General de Proyectos de Arquitectura, Ministerio de Desarrollo Urbano, GCBA. 


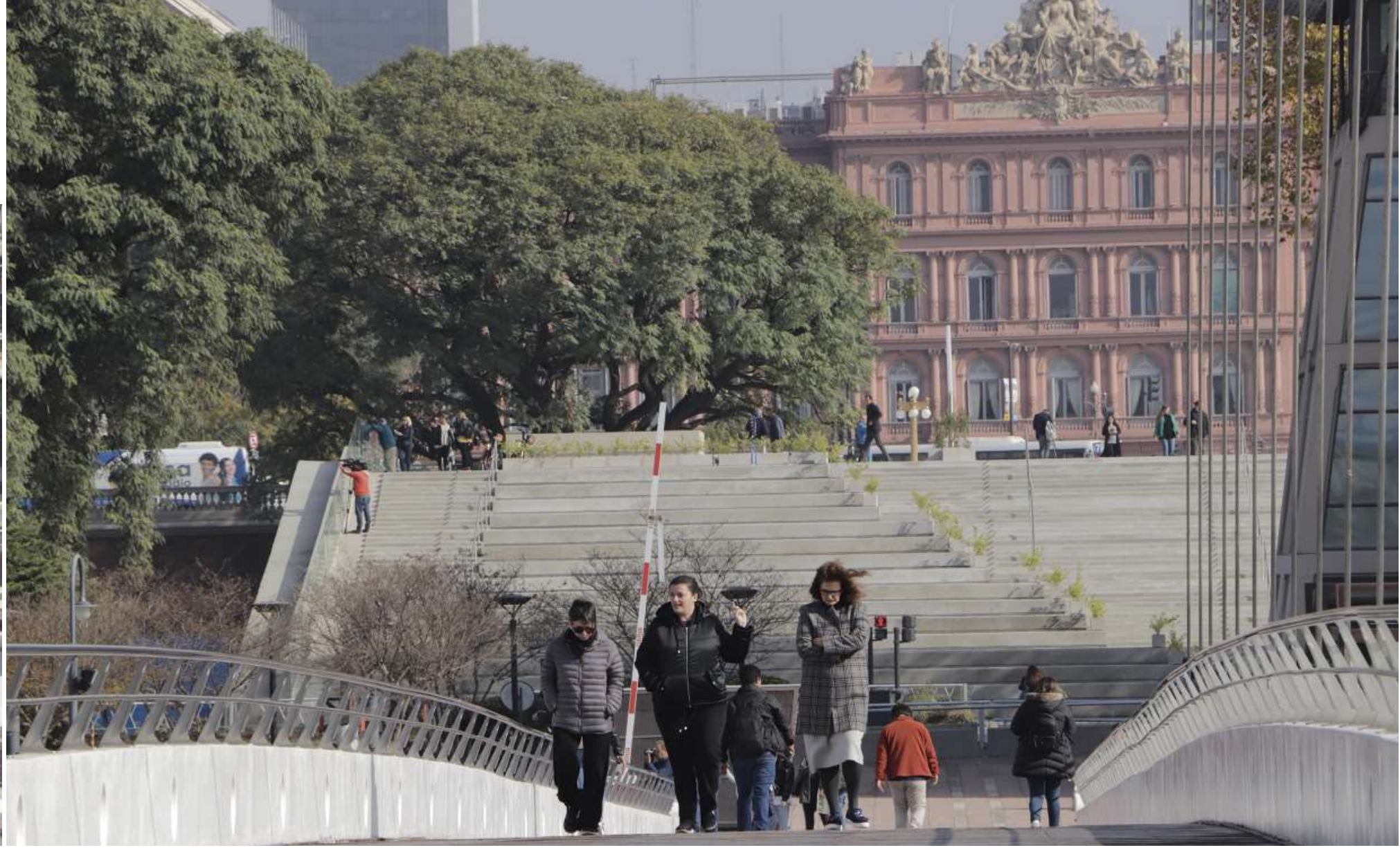

Figura 5. Sector Parque lineal del Bajo, escalera que comunica la Casa de Gobierno con Puerto Madero. Vista desde el Puente de la Mujer. Ciudad Autónoma de Buenos Aires, 2019. Fuente: Dirección General de Proyectos de Arquitectura, Ministerio de Desarrollo Urbano, GCBA.

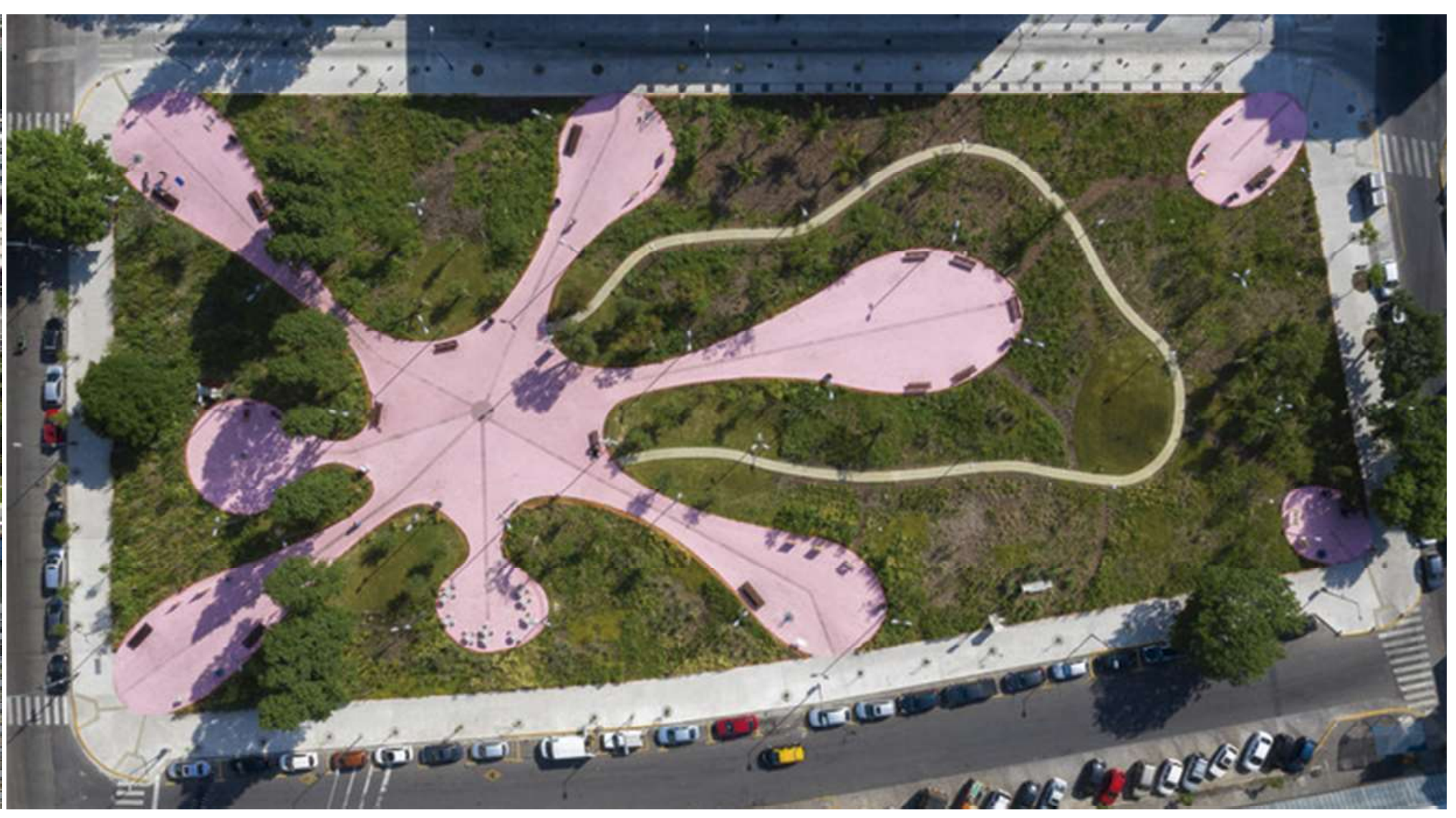

Figura 6. Plaza Clemente, Ciudad Autónoma de Buenos Aires, 2019.

Fuente: fotografía de Javier Rojas para la Dirección General de Proyectos de Arquitectura, Ministerio de Desarrollo Urbano, GCBA. 
un dibujo del artista plástico argentino Pablo Siquier. (Figura 7)

En estos cuatro años el espacio público fue un eje importante en la gestión del Gobierno de la Ciudad de Buenos Aires. Además de las obras descritas, cabe mencionar otros ejemplos como la peatonalización de la avenida Corrientes en el sector donde se concentran los teatros y las librerías, la recuperación de la histórica plaza de los Tribunales y la puesta en valor del parque Lezama.

\section{Sin embargo... no todo lo que brilla...}

En la avenida Diagonal Norte, avenida tradicional del centro histórico porteño, se encuentra un puesto de lustrabotas con la frase "Una ciudad que crece con mucho briIlo". (Figura 8) Con las obras mencionadas, tal como se publicita en dicho afiche, la ciudad parece brillar. Sin embargo una mirada desde otra perspectiva lleva a reconocer, en ese mismo espacio público, síntomas de disconformidad social de gran parte de la población. Pareciera prevalecer otra lógica urbana donde el espacio público se transforma en el espejo de las falencias y necesidades de gran parte de la población que vive y/o utiliza la ciudad.

Al respecto también vale recordar a Michel De Certeau cuando define la calle como "geométricamente definida por el urbanismo que se transforma en espacio por la intervención de los caminantes" (2007). Caminantes que van introduciendo sus diferentes improntas más allá de los senderos planificados. Es en su libro La invención de lo cotidiano donde De Certeau desarrolla esta idea del espacio como escenario de la resistencia ciudadana precisando de qué manera las prácticas de la resistencia hacen una apropiación crítica y selectiva de las prácticas disciplinarias, modificando su sentido y carácter. Así, constata la existencia de modos alternativos que interactúan en el espacio. (De Certeau, 2007)

Hoy, en la ciudad de Buenos Aires, el espacio público que brilla es el mismo que refleja la calidad de vida de una gran parte de la población que está sufriendo los coletazos de una política económica errática que en los últimos cuatro años ha hecho aumen- tar la desocupación y la pobreza de manera desmesurada.

La coexistencia de la pobreza y la rique$z a$, en diversos grados y formas, ha sido una característica de las áreas metropolitanas latinoamericanas. Sin embargo, en los últimos años, como resultado de las políticas neoliberales y la configuración de una economía global como forma del capitalismo avanzado, las diferencias se han acentuado pasándose de la pobreza a la exclusión social y económica y consolidándose un modelo socio-territorial fragmentado y de segregación urbana. En los últimos cuatro años, la Ciudad de Buenos Aires, aun siendo el distrito con el mayor ingreso per cápita del país, no escapó al empobrecimiento provocado por esas políticas económicas. Es así que el brillo de importantes obras en el espacio público se ve opacado por la cantidad de locales comerciales cerrados, en venta o alquiler; la proliferación de vendedores ambulantes, familias enteras viviendo en las calles y personas revolviendo la basura en busca de comida.

Acorde a datos de la Dirección General de Estadísticas y Censos de la Ciudad Autónoma de Bs As., en el primer semestre del 2019 , el $6 \%$ de la población de la CABA se encontraba en situación de indigencia, el $14,6 \%$ en situación de pobreza, el $10,8 \%$ en situación vulnerable, siendo un $10,2 \%$ considerado como sector medio frágil y dando así un total del $41,6 \%$ de la población de la ciudad con algún nivel de deterioro en su capacidad económica. El 48,5\% correspondía al sector medio y el $9,9 \%$ al sector acomodado.

Tomando como fuente al Observatorio de la Deuda Social Argentina de la Universidad Católica Argentina, durante el 2019 se registró un $9 \%$ de población de la Ciudad Autónoma de Buenos Aires en situación de pobreza multidimensional ${ }^{7}$ mientras que en los municipios del área metropolitana que la rodea alcanzó al $47,7 \%$, siendo estos los valores más altos de la década. ${ }^{8}$

Políticas erráticas, incluyendo reiteradas devaluaciones, aumento desproporcionado de la inflación (aproximadamente 48,3\% anual), regresiva distribución del ingreso, 
precarización laboral, aumento del desempleo junto a las medidas de ajuste acordadas con el Fondo Monetario Internacional, explican en parte el importante deterioro social.

El espacio público resulta entonces el escenario del creciente malestar social. La pobreza, la marginación y el descontento se presentan en ese mismo espacio público tantas veces pensado como el lugar de la sociabilidad y de unidad entre sociedad y Estado, ponderado como espacio "neutral". El espacio público en este contexto deja de ser aquel lugar donde las desigualdades parecían esfumarse o disimularse, el lugar para todos por igual, para ser el lugar donde el Estado intenta enmascarar la realidad asimétrica de las relaciones sociales que administra. (Delgado, 2007)

\section{Conclusiones}

De esta manera, en los últimos tiempos, el espacio público aparece como espejo donde ver reflejadas prioritariamente las distintas necesidades y falencias sociales. También en ciudades de diferentes continentes, distantes entre sí, comienzan a producirse manifestaciones populares y masivas, estallidos "inesperados" y detonantes que parecen insignificantes al lado de la importancia de la demostración producida. París, Santiago de Chile, Beirut, Quito, son apenas algunas de las ciudades donde estos hechos se reproducen. $Y$ es probable que en esas ciudades también haya habido en el espacio público rastros del malestar que no quisieron verse.

Pareciera ser que hoy es en el espacio público donde más se visibilizan las demandas concretas y las injusticias sociales, se condensan las múltiples tensiones y las contradicciones.

Sin embargo, la incomprensión de las dinámicas en curso y el desconocimiento de la sociedad real por parte de los gobernantes se traducen en el motor de los estallidos. Rápidamente se movilizan miles de personas sin líderes ni organizaciones formales que en general son rechazadas con una represión que solo logra provocar el aumento de las demandas.

Es en el espacio público de las grandes ciudades donde de manera creciente aparecen las muestras de las desigualdades y el consecuente malestar de la población postergada, convirtiéndose en el ámbito más significativo del conflicto urbano y social, siendo ésta en la actualidad la dimensión preponderante y a la que sin dudas hay que prestarle mayor atención.

'El aire de la ciudad nos hace libres', solía decirse. Pues bien: hoy el aire está un poco contaminado; pero puede limpiarse. (Harvey, 2008)

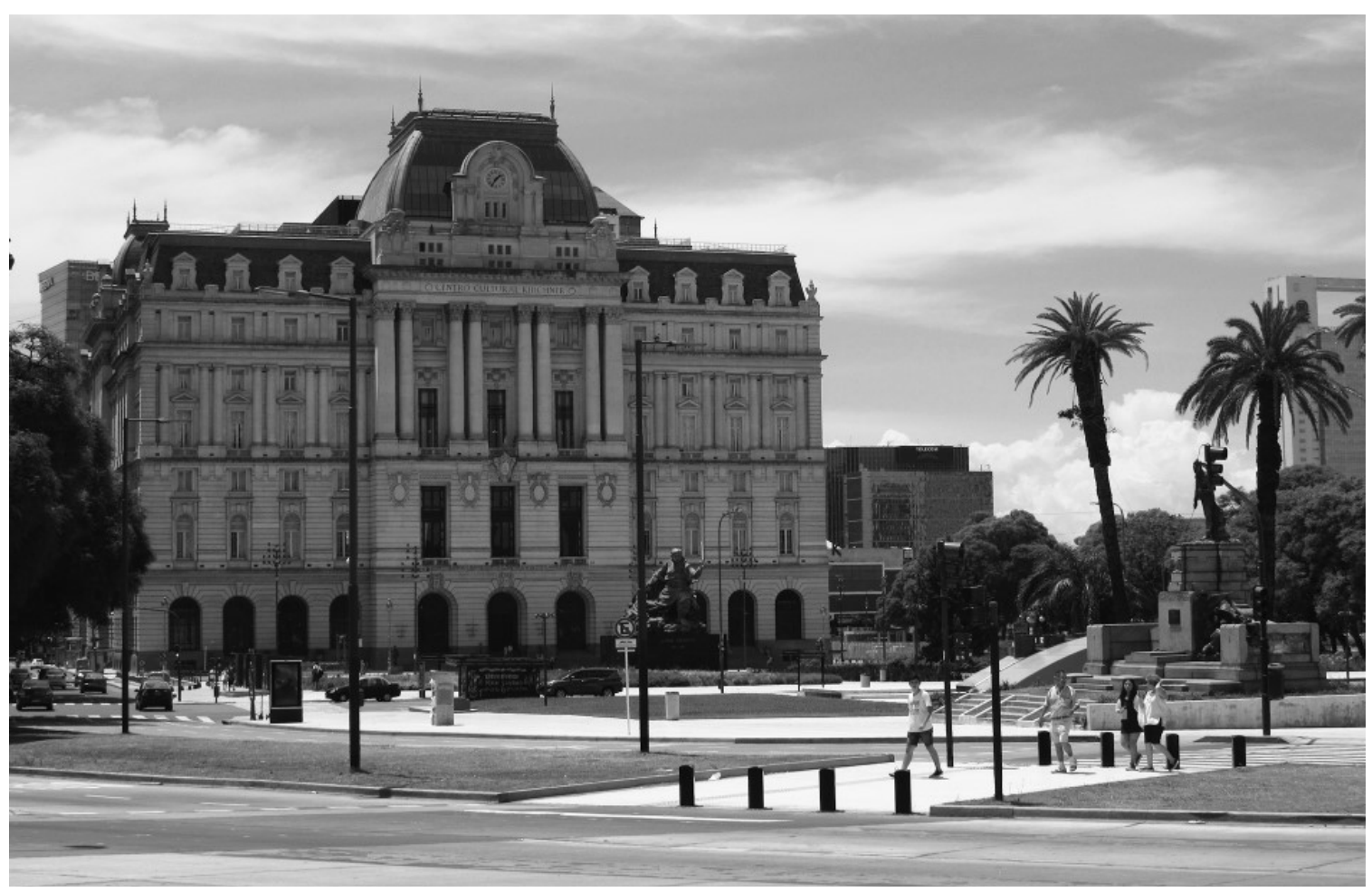




\section{Notas}

1 La Organización Mundial de la Salud establece la necesidad de que cada ciudad tenga como mínimo $9 \mathrm{~m} 2$ de área verde por habitante. Según el Gobierno de la Ciudad, Buenos Aires tiene $6 \mathrm{~m} 2$ por habitante y muy mal distribuidos según los barrios.

2 La Ciudad de Buenos Aires goza de autonomía a partir de la reforma de la Constitución Nacional de 1994, en la cual a través del art. 129 se le otorgó a la ciudad un régimen de gobierno autónomo con facultades de legislación y jurisdicción y se estableció la elección directa del Jefe de Gobierno por parte del pueblo de la ciudad. (Constitución Nacional, 1994). Este sistema fue reglamentado posteriormente en la Constitución de la Ciudad de 1996 donde se estableció su régimen republicano con tres poderes (ejecutivo, legislativo y judicial), órganos de control y un sistema comunal. A partir de entonces la Ciudad de Buenos Aires funciona en forma autónoma a la vez que sigue siendo la capital del país.

3 De estos 24 municipios que conforman el conurbano bonaerense, 13 están totalmente urbanizados y 11 poseen también áreas rurales. Mucha de la población que habita en el conurbano trabaja y vive la mayor parte del día en la CABA utilizando sus hospitales, escuelas e infraestructura en general.

4 Esta obra fue el resultado de un concurso de ideas convocado por la Sociedad Central de Arquitectos en conjunto con la Corporación Antiguo Puerto Madero S.A. y el Ministerio de Desarrollo Urbano y Transporte de la CABA; resultando ganador el equipo integrado por los arquitectos Daniel Becker, Sergio Cavalli, Joan Marantz y Agustín Olivieri.
5 En sintonía con los emprendimientos de revalorización de áreas costeras degradadas en otros países, la urbanización de Puerto Madero significó la reconversión de una zona portuaria sin actividad, en una localización privilegiada lindante al área central. Su desarrollo implicó nuevos mecanismos de gestión y articulación entre la administración pública y los inversores privados. Mediante la Ordenanza №26.607 del año 1972 se estableció la división de la ciudad en cuarenta y seis barrios porteños. En el año 1996, la Ordenanza $N^{\circ} 51.163$ incorporó a Puerto Madero como nuevo barrio de la ciudad.

6 El Puente de la Mujer fue diseñado por el arquitecto Santiago Calatrava y fabricado en el País Vasco, España, con un acero que no se fabrica en Argentina. Cruza el Dique 3, siendo sus dimensiones 170 metros de largo y 6, 20 metros de ancho. Su imagen se asemeja a la síntesis de una pareja bailando tango.

7 El Índice de Pobreza Multidimensional es un indicador desarrollado en base a la metodología del Programa de Naciones Unidas para el Desarrollo (PNUD), elaborado con información proveniente de tres dimensiones: salud, educación y condiciones habitacionales.

8 Otro dato que marca la gran diferencia entre la ciudad nuclear y los municipios del área metropolitana es el que se obtiene de dividir el presupuesto anual de cada municipio sobre su cantidad de habitantes. Así mientras que el recurso per cápita en CABA es de \$110000 por porteño, en el otro extremo se encuentra el municipio de La Matanza, municipio limítrofe de la Ciudad Autónoma de Bs As, con 2,1 millones de habitantes y apenas $\$ 4760$ per cápita.

\section{Referencias bibliográficas}

Bohigas, O. (2008) Entrevista, Revista Promateriales nº 20.

Borja, J. (2003) La ciudad conquistada. Alianza Editorial.

Carrión, F. (2004) Espacio público, punto de partida para la alteridad. Ciudad e inclusión: por el derecho a la ciudad. Gente Nueva Editorial.

Ciccolella, P.; Mignaqui, I. (2009) Globalización y transformaciones de la centralidad histórica en Buenos Aires. Revista de la Organización Latinoamericana y del Caribe de Centros Históricos, n 3, p 91-101.

De Certeau, M. (2007) La invención de lo cotidiano. 1-Artes de hacer, Universidad Iberoamericana.

Delgado, M; Malet, D. (2007) El espacio público como ideología. Jornadas Marx siglo XXI, Universidad de la Rioja.

Dirección General de Estadísticas y Censos (2019) Buenos Aires en números, año $6, n^{\circ} 6$, Gobierno de la Ciudad de Buenos Aires.

García Canclini, N. (1997) Imaginarios urbanos. Editorial Universitaria de Buenos Aires.
Lefebvre, H. (2013) La producción del espacio. Capitán Swing Libros S. L.

Harvey, D. (2008) El derecho a la ciudad. www.rebelión. org

Segovia, O.; Jordán, R. (2005) Espacios públicos urbanos, pobreza y construcción social. Serie medio ambiente y desarrollo, CEPAL.

Vapñarsky, C. (1996) Buenos Aires metrópoli: una comunidad local, una aglomeración, veintiseis municipios, en: Herzer, $\mathrm{H}$ (compiladora), Ciudad de Buenos Aires. Gobierno y descentralización. Colección CEA$\mathrm{CBC}$, Universidad de Buenos Aires.

\section{Página de internet.}

Observatorio de la deuda social argentina de la Universidad Católica Argentina. Avance del informe deudas sociales y desigualdades estructurales en la Argentina 2010-2019 - Aportes para una agenda sustentable del desarrollo humano Integral. http:// uca.edu.ar/es/observatorio-de-la-deuda-social-argentina 


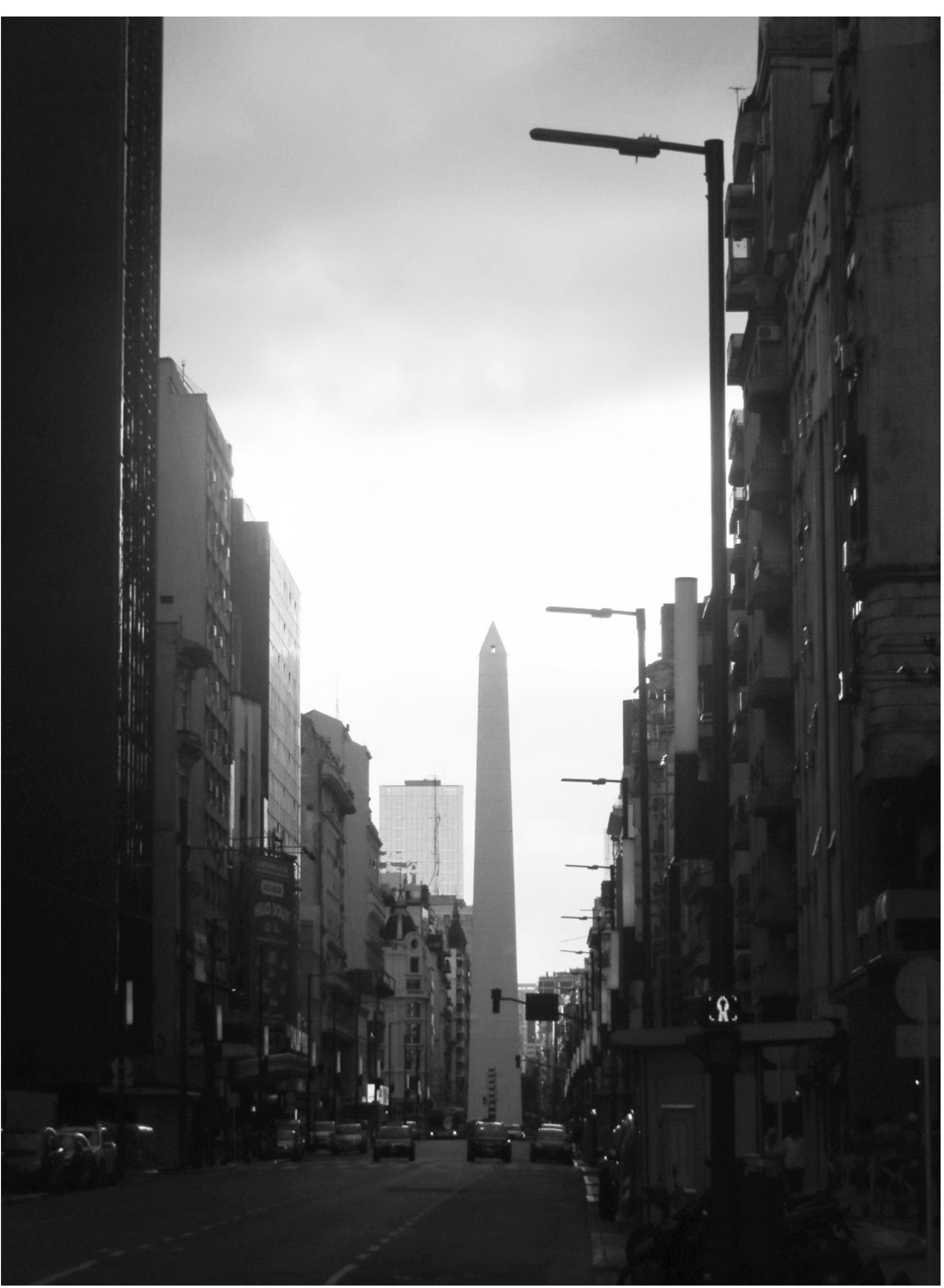

